\title{
Turist Rehberlerinin Gastronomiye Yönelik Bilgi ve Algı Düzeylerinin Tavsiye Niyetine Etkisi: Kapadokya Örneği
}

\section{The Effect of Tourist Guides on the Recommendation of Knowledge and Perception Levels of Gastronomy: Case of Cappadocia}

\author{
Dr. Öğr. Üyesi Emrah KESKiN \\ Nevşehir Hacı Bektaş Veli Üniversitesi \\ Turizm Fakültesi, Nevşehir, Türkiye \\ E-posta: ekeskin@nevsehir.edu.tr
}

\author{
Arş. Gör. Dr. Şule ARDIÇ YETiŞ \\ Nevşehir Hacı Bektaş Veli Üniversitesi \\ Turizm Fakültesi, Nevşehir, Türkiye \\ E-posta: ardicsule@nevsehir.edu.tr
}

\author{
Bülent YORGANCI \\ Nevşehir Hacı Bektaş Veli Üniversitesi \\ Sosyal Bilimler Enstitüsü, Nevşehir, Türkiye \\ E-posta: bulentyor@yahoo.com
}

\section{Öz}

Gastronomi turizmine yönelik seyahatlerin popüler olması bölge rehberlerinin de kendilerini gastronomi konusunda geliştirmelerini zorunlu kılmaktadır. Turist rehberlerinin gastronomiye yönelik bilgi ve algılarının artırılması, bölgenin yeme-içme kültürünün tavsiye edilmesine de katkı sağlar. Bölgelerin gastronomik değerlerinin tanıtımı açısından önemli bir fonksiyona sahip olan turist rehberlerinin gastronomi bilgisi ve gastronomiye yönelik algılarının, tavsiye niyeti ile olan ilişkisini ölçmeyi amaçlayan bu çalışma Nevşehir Rehberler Odası'na (Nero) kayıtlı olan rehberlerden elde edilen 211 anket verisinin analiziyle gerçekleştirilmiştir. Araştırmada analizler SPSS ve AMOS programları kullanılarak güvenirlik, faktör ve korelasyon analizleri yapılmıştır. Araştırma sonucunda, turist rehberlerinin gastronomi bilgisi ve gastronomi algısının tavsiye niyeti üzerinde etkili olduğu belirlenmiştir.

Anahtar Kelimeler: Gastronomi, Gastronomi Bilgisi, Gastronomi Algısı, Tavsiye Niyeti, Turist Rehberi

\begin{abstract}
The popularity of travels related to gastronomy tourism necessitates regional guides to develop themselves in gastronomy. Increasing the knowledge and perceptions of tourist guides towards gastronomy also contributes to the recommendation of the region's food and drink culture. This study, which aims to measure the relationship between tourist guides, who have an important function in terms of promoting the gastronomic values of the regions, and their perception of gastronomy, with the intention to recommend, was carried out by the analysis of 211 survey data obtained from the guides registered with Nevsehir Chamber of Guides (NERO). Research analysis were done using reliability, factor and correlation analysis by SPSS and Amos programs. As a result of the research it has been determined that tourist guides have an influence on gastronomic knowledge and on the recommendation of the perception of gastronomy.
\end{abstract}

Key Words: Gastronomy, Gastronomy Knowledge, Gastronomy Perception, Recommendation Intention, Tourist Guide 


\section{Extensive Summary}

\section{Purpose}

Cappadocia, one of the most important tourism center of Turkey, has begun to come to the forefront with its gastronomic values. The launching of tours for local gastronomic products of the region and the visits of those who are interested in gastronomy to the region has started to increase the importance given to gastronomic tourism in the region. Studies indicate that Cappadocia has gastronomic values and it shows that presenting these values to incoming tourists will contribute to the region. Therefore, gastronomy information and perceptions of tourist guides can be effective in advising guests.

\section{Background}

Utensils can be completed in a touristic environment or can be defined as a touristic value on their own. Therefore, gastronomy is important in the recognition and branding of destinations. Food and beverage culture is at the root of the concept of gastronomy. Touristic activities for this purpose contribute to the creation of gastronomic themed visits in order to learn this culture. Gastronomic tourism contributes to tourists visiting the destination to learn about the region's food and beverage culture and to experience new foods.

Tourist guides are the people who are most interested in the desires, expectations and suggestions of the tourists during the travels to the destinations. People who professionally perform the tourist guidance profession are considered as the tourism ambassadors of the countries. Tourist guides are expected to have information about the historical, natural and cultural structure of the destination and to convey this information. Among the information conveyed to tourists, gastronomy values of destinations should also be included. For this reason, professional tourist guides should have knowledge about the regional cuisine and share their acquisitions in this area with tourists.

\section{Method}

Since gastronomy tourism is accepted as one of the important tourism types of today, the knowledge levels and perspectives of gastronomy in this field are considered important. Based on this point, this study aims to determine the gastronomy information and perception of gastronomy of the people who serve as professional tourist guides in the Cappadocia region and to measure the effect of these elements on the recommendation intention.

The universe of the study is the guides registered with Nero (Nevsehir Chamber of Guides). According to 2020, TUREB statistics, it was determined that there are 637 active and 103 inactive guides registered with Nero. Due to the limited universe, no sampling was provided the whole universe (active guides) was reached. As a result of interviews with the guides, 240 guides volunteered to participate in the study and accepted the questionnaire. As a result of the survey application, 211 questionnaires were found suitable for the analysis. 


\section{Findings}

When the findings obtained in the research section of this study were examined, it was determined that there was a positive and significant relationship between the gastronomy knowledge, perception of gastronomy and the intention of recommendation. As a result of the obtained results, hypotheses were accepted. According to the findings, it can be said that gastronomy knowledge and perception of gastronomy are important in the advice intent of tourist guides. When the data are analyzed, it has been determined that the perceptions of tourist guides in their recommendation intentions towards gastronomy are more effective than their gastronomy knowledge. As a result of the obtained outcome improving the gastronomy knowledge and perception of the people who are guiding in Cappadocia can contribute to the recommendation of the region. Therefore, if the region's gastronomic values can be taught to the guides and the perception towards gastronomy can be created, it can contribute to the development of gastronomic tourism.

\section{Results}

As a result of this research, it should be ensured that the tourist guides have an effective role in promoting the food culture of the destinations, and therefore gastronomy lessons should be included in the tourism or tourist guidance departments of the universities. Because today, tourists are also travelling to experience local delicacies and can request a gastronomic guide in it. For this reason, programs that will enable guides to gain knowledge in the field of gastronomy can be created. The guides can make a positive contribution to the image of the region by transferring regional gastronomy to tourists more accurately. Thanks to this positive image, it can be effective for tourists to visit the region again. In addition, more researches examining the relationship between tourist guidance and gastronomic tourism can be carried out and conscious and equipped guides about gastronomy can be trained.

*Bu çalışmanın Nevşehir Hacı Bektaş Veli Üniversitesi Sosyal ve Beşeri Bilimler Araştırmaları Etik Kurulu Yönergesinde belirtilmiş etik ilkelere uygun olduğuna karar verilmiştir. Karar tarih:02.03.2020 Karar Numara:7

\section{Giriş}

Turistik açıdan çok sayıda çekicilik unsuruna sahip olan Türkiye, elinde bulundurduğu bu değerler ile dünyanın önemli destinasyonlarından birisi olarak kabul görmektedir. Son zamanlarda dünya turizminde yaşanan değişime ve insanların boş zamanlarındaki aktivitelerine bağlı olarak tatil anlayışlarında da farklılıklar meydana gelmiş ve insanlar farklı nedenlerle seyahatlere yönelmeye başlamışlardır (Kozan, Özdemir ve Günlü, 2014; Yayla ve Çetiner, 2019). Turizm sektöründeki yoğun rekabet işletmeleri sahip oldukları kaynakları daha iyi yönetmeye zorlamaktadır (Solunoğlu, 2019; Güneren vd., 2016). İşletmeler ellerindeki kaynakları iyi kullandıkları zaman başarılı olacak ve bu yolla turist çekim merkezlerinden birisi haline geleceklerdir. Destinasyonların sahip oldukları kaynaklar arasında gastronomik unsurlar oldukça önemli görülmektedir. Bu nedenle destinasyonlar sahip olduğu gastronomi kültürünü iyi analiz ettiklerinde çekim güçlerini de artırabilirler.

Destinasyonların sahip olduğu yiyecek-içecek ürünleri ve geçmişten beri süre gelen mutfak kültürleri, turistik ürünlerin tamamlayıcısı olabildiği gibi kendi başlarına da bir turistik değer olarak tanımlanabilir. Bu nedenle gastronomi destinasyonların bilinirliği ve markalaşmasında önemlidir (Eren, 2016). Gastronomi kavramının 
kökeninde yiyecek ve içecek kültürü yer almaktadır. Bu amaca yönelik meydana getirilen turistik faaliyetler ise bu kültürün öğrenilmesi amacıyla gastronomi temalı ziyaretlerin oluşturulmasına katkı sağlar. Gastronomi turizmi destinasyonu ziyaret eden turistlere, bölgenin yiyecek-içecek kültürünü öğrenmelerine, yeni yiyecekleri deneyimlemelerine katkı sağlar (Akbaba ve Kendirci, 2016). Destinasyonların sahip olduğu gastronomi değerleri markalaşma ve bilinirlik açısından oldukça önemlidir. Destinasyona ait mutfak kültürü ve yemeklerin ortaya çıkarılması bölgeyi, ziyaret eden turistlerin destinasyon gastronomisine ilgi duymalarına ve gastronomi turizmine yönelmelerine katkı sağlar (Özaltaş ve Serçek, 2015; Aksoy ve Sezgi, 2015). Bu nedenle gastronominin destinasyonların markalaşmasında etkili bir güç olduğu söylenebilir.

Destinasyonlara gerçekleştirilen seyahatlerde turistlerin istek-arzu, beklenti ve önerileriyle en fazla ilgilenen kişiler turist rehberleridir. Profesyonel olarak turist rehberliği mesleğini gerçekleştiren kişiler ülkelerin turizm elçileri olarak nitelendirilmektedir. Turist rehberlerinin destinasyonun tarihi, doğal ve kültürel yapısı hakkında bilgi sahibi olması ve bu bilgiyi aktarması beklenir (Köroğlu vd., 2007; İrigüler ve Güler, 2017). Turistlere aktarılan bilgiler arasında destinasyonların gastronomi değerleri de yer almalıdır. Bu nedenle profesyonel turist rehberleri bölge mutfağı hakkında bilgi sahibi olmalı ve bu alanda elde ettiği edinimleri turistlerle paylaşmalıdır.

Gastronomi turizmi günümüzün önemli turizm çeşitlerinden birisi olarak kabul gördüğü için rehberlerin bu alana yönelik bilgi seviyeleri ve gastronomiye bakış açıları önemli görülmektedir. Bu noktadan hareketle bu çalışma Kapadokya bölgesinde profesyonel turist rehberi olarak görev yapan kişilerin gastronomi bilgileri ve gastronomi algılarını belirlemeye ve bu unsurların tavsiye niyetine etkisini belirlemeyi amaçlamıştır. Bu çalışma, destinasyonları ziyaret eden turistler ile birebir etkileşim halinde olan ve destinasyonun en önemli tanıtım elçilerinden biri olan turist rehberlerinin destinasyonun gastronomik unsurlarına yönelik algılarını geliştirmeye yönelik öneriler sunması ve destinasyonların sadece sahip olduğu tarihi ve doğal güzellikleri ile değil, aynı zamanda somut olmayan kültürel miras unsurlarından biri olan gastronomi ile bilinirlik kazanması açısından önem taşımaktadır.

\section{Literatür Taraması}

Dünya üzerinde turizm amaçlı seyahatlere katılanların seyahate yönelme nedenlerinden bir tanesi mutfak kültürüdür. Destinasyonların yeme-içme kültürleri turistik çeşitlendirmede ve turistik değer meydana getirmede önemli bir role sahiptir. Türkiye sahip olduğu mutfak kültürü ve bu kültürün ortaya çıkardığı tatlar açısından oldukça gelişmiş bir gastronomi destinasyonudur (Horng ve Tsai, 2012; Bucak Aracı, 2013). Gastronomi potansiyeli açısından oldukça zengin değerlere sahip olan Türkiye, elinde bulundurduğu bu zenginliğe rağmen gastronomi turizminde çok gelişme gösterememiştir. Bunun en önemli sebeplerinden birisi Türkiye destinasyonunun denizkum-güneş destinasyonu olarak tanımlanması ve pazarlama aşamasında bu öğelerin ön plana çıkarılmasıdır. Gastronomi temalı yapılan etkinliklerin geliştirilmesi ve tanıtımının iyi yapılması Türkiye gastronomi turizminin gelişiminde etkilidir (Bilgili vd., 2012). Bu nedenle turistik bölgelerin turistlere tanıtılmasında ve farklılık oluşturulmasında gastronomi turları önemlidir (Kivela ve Crotts, 2006). Destinasyonlar sahip olduğu değerler açısından incelendiğinde bazıları doğal güzelliklere, bazıları kültürel değerlere sahip olmakla birlikte her destinasyonun az veya çok sahip olduğu belirli bir yeme-içme kültüründen söz edilebilir. Bu nedenle destinasyonların yeme-içme kültürü hakkında turistlerin bilgilendirilmesi ve turistlere farklılık yaşatılması memnuniyet açısından önemlidir. Turistlerin tatillerinden azami fayda elde etmelerinde 
turist rehberlerinin etkisi büyüktür. Destinasyon ziyareti esnasında turistler ile etkileşimde bulunan turist rehberleri turistleri yerel kültürler hakkından bilgilendiren ve onları yönlendiren kişilerdir. Yerel kültürün öğretilmesi, var olan mirasın devam ettirilmesi ve destinasyona gelen turistlerin memnun ayrılmasında büyük bir öneme sahip olan turist rehberleri destinasyon hakkında bilgi sahibi olmak zorundadırlar (Uslu ve Kiper, 2006; Ling vd., 2011). Destinasyonun gastronomi kültürü ve yeme-içme adetleri de turist rehberlerinin tura katılan müşterileri etkilemede kullandığı önemli konulardandır. Bu nedenle rehberlerin bölge gastronomisi hakkında bilgi sahibi olmaları önemli görülmektedir (Karamustafa ve Çeşmeci, 2006). Akay ve Özöğütçü (2018), yapmış oldukları çalışmada turist rehberlerinin sahip oldukları bilgi seviyelerinin turistlere sunulan tavsiyelerde etkili olduğunu belirtmişlerdir. Bir diğer nokta ise turist rehberlerinin gastronomiye yönelik algılarıdır. Turist rehberlerinin gastronomi öğelerine yönelik algı seviyelerinin artırılması turlara katılan turistlerin gastronomiye yönelik ilgilerinin artırılmasına ve destinasyonun gastronomik öğelerine yönelimi de artırabilir. Temel rolü destinasyonu ziyarete gelen turistlere bilgi aktarma olan turist rehberlerinin algılarına yönelik çalışmalar incelendiğinde; rehberlerin kültürel değerlerin korunması, bölgenin tanıtılması ve kültürlerarası etkileşime katkı sağlaması sonuçları ortaya çıkmaktadır (Aslan ve Çokal, 2016). Gastronomik öğeler de bir destinasyonun önemli kültürel değerlerinden birisidir. Bu nedenle gastronomiye yönelik algının güçlendirilmesi turistlerin kültürlerarası etkileşiminin artırılmasına ve bölgenin gastronomi değerlerinin sürdürülebilir hale getirilmesine katkı sağlayacaktır.

Gastronomi, bir bölgeye ziyaret etme niyeti içinde olan potansiyel turistleri efektif turist haline getirebilen, destinasyon seçimi üzerinde önemli bir etkiye sahip olan ve destinasyon tanıtımında sıklıkla kullanılan pazarlama unsurlarından birisidir (Hjalager ve Corigliano, 2000; Gürsoy ve Mcleary, 2004; Yılmaz ve Özdemir, 2015). Bundan dolayı destinasyonlar gastronomilerine önem vermeli ve bu değerlerin bilinirliğinin artırılmasına katkı sağlamalıdırlar.

Türkiye'nin önemli turizm merkezlerinden bir tanesi olan Kapadokya bölgesi sahip olduğu gastronomi değerleriyle de ön plana çıkmaya başlamıştır. Bölgenin yerel gastronomi ürünlerine yönelik turların düzenlenmeye başlaması ve gastronomiye ilgi duyanların bölgeye ziyaretlerinin başlaması bölgede gastronomi turizmine verilen önemi artırmaya başlamıştır. Aslan vd. (2014), Kapadokya bölgesinin yöresel yemeklerinin turistler tarafından tercih edilme düzeylerinin yüksek olduğunu ifade etmişlerdir. Yılmaz (2017), bölgeyi ziyarete gelen turistlerin damak tatlarına uygun yemeklerin üretilmeye başlandığını ve gastronomik değere sahip turistik ürün çeşitliliğinin arttığını belirtmiştir. Katlav vd. (2019) ise Kapadokya bölgesi gastronomi turizminin geliştirilebilir potansiyele sahip olduğunu ve bunun da bölge turizmine olumlu katkılarının olacağını ifade etmişlerdir. Yapılan çalışmalar Kapadokya bölgesinin gastronomi değerlerinin olduğunu ve bu değerlerin gelen turistlere sunulmasının bölgeye katkı sağlayacağının kanıtıdır. Bu nedenle turist rehberlerinin gastronomi bilgileri ve algıları misafirlere tavsiyelerinde etkili olabilir. Zengin ve Eker (2014), yaptıkları çalışmada turist rehberlerinin kültür turizminin sürdürülebilirliğinde ve kültürel değerlerin misafirlere tanıtımasında önemli bir fonksiyona sahip olduklarını belirtmiştir. Anderson vd. (2004) ise, destinasyon ziyareti esnasında turistlerin aynı restoranları seçmelerinde tavsiyenin etkili olduğunu belirtmişlerdir. Bu nedenle Kapadokya destinasyonu temelli turist rehberlerinin gastronomi hakkında bilgi sahibi olmaları veya özel alan olarak gastronomi rehberliğine yönelmeleri bölgeye gelen turistlerin gastronomi turizmine katılmalarına veya gastronomi temasına yönelik gelişlerin oluşmasına katkı sağlayabilir. 


\section{Metodoloji}

\subsection{Araştırmanın Amacı, Önemi ve Modeli}

Günümüzün önemli turizm türlerinden birisi haline gelmeye başlayan gastronomi turizmi, destinasyonların mutfak kültürlerini ortaya çıkaran ve mutfağa ilgi duyan turistlerin destinasyon tercihlerine pozitif yönde etki eden turizm türlerinden birisi haline gelmiştir. Bu nedenle destinasyon yöneticileri gastronomik değerlerini geliştirmeye ve tanıtımına önem vermeye başlamışlardır. Turistik destinasyonların sahip olduğu gastronomi ile alakalı ürünlerin bölgeye gelen turistlere sunulmasında turist rehberlerinin rolü çok önemlidir. Turist rehberlerinin konu hakkında bilgi sahibi olmaları ve gastronomiye bakış açıları turistlere bölgenin gastronomi değerlerini tavsiye etmelerinde oldukça önemli görülmektedir. Bu noktadan hareketle çalışmada önemli bir turizm destinasyonu olan Kapadokya Bölgesi'nde görev alan turist rehberlerinin gastronomi bilgisi ve algısının tavsiye niyetine etkisinin belirlenmesi amaçlanmıştır. Turist rehberlerinin gastronomiye yönelik bilgi ve algı seviyelerinin belirlenmesi ve artırılması bölgeyi ziyaret eden turistlere yeme içme deneyimleri yaşatılması açısından önemli görülmektedir. Bu önemden hareketle belirlenen amaç doğrultusunda çalışma modeli ve modele bağlı kalarak iki hipotez belirlenmiştir.

\section{Şekil 1: Araştırma Modeli}

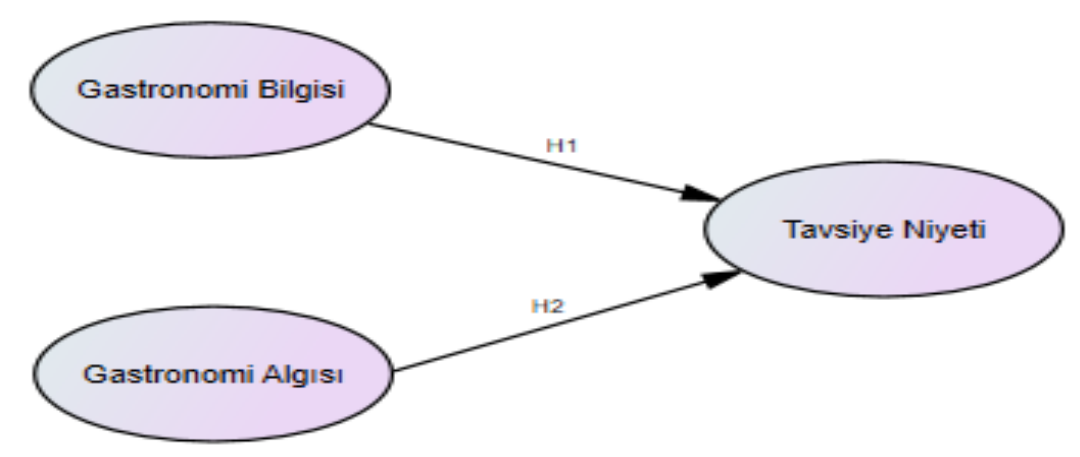

H1: Turist rehberlerinin gastronomi bilgisi ile tavsiye niyeti arasında pozitif yönlü ve anlamlı bir ilişki vardır.

H2: Turist rehberlerinin gastronomi algısı ile tavsiye niyeti arasında pozitif yönlü ve anlamlı bir ilişki vardır.

Belirlenen hipotezlerin analizi için Özöğütçü (2018) tarafından geçerlilik ve güvenirlik analizleri yapılan gastronomi bilgisi (beş madde ve tek boyut), gastronomi algısı (beş madde ve tek boyut) ve tavsiye niyeti (dört madde ve tek boyut) ölçeği kullanılmıştır.

Çalışmanın uygulanabilmesi için gerekli olan etik kurul izni alınmıştır (Bu çalışmanın Nevşehir Hacı Bektaş Veli Üniversitesi Sosyal ve Beşeri Bilimler Araştırmaları Etik Kurulu Yönergesinde belirtilmiş etik ilkelere uygun olduğuna karar verilmiştir. Karar tarih:02.03.2020 Karar Numara:7). Çalışmanın evrenini Nevşehir Rehberler Odası'na (Nero) kayıtlı rehberler oluşturmaktadır. 2020 TUREB istatistiklerine göre Nero'ya kayıtlı 637 eylemli, 103 eylemsiz rehberin bulunduğu tespit edilmiştir (TUREB, 2020). Evrenin sınırlı olması nedeniyle örnekleme gidilmemiş, bütün 
evrene (eylemli rehberler) ulaşılmaya çalışılmıştır. Çalışmanın yapıldığı Mart-Nisan aylarında COVID-19 Pandemi sürecinin olması nedeniyle tamsayım yapılamamıştır. Rehberlerle yapılan sanal ön görüşmeler neticesinde 240 rehber çalışmaya katılmaya gönüllü olmuş ve anket uygulamasını kabul etmişlerdir. Anket uygulaması sonucunda eksik olan veya yanlış beyan verdiği tespit edilen anketler çıkarılarak 211 tanesi istatistikî verilerde kullanılabilecek düzeyde geri gelmiştir. Bu kapsamda çalışma evreni $\% 29$ oranında temsil edebilmektedir.

\section{Bulgular}

Literatüre bağlı kalınarak geliştirilen modelin analizi için Amos 21 paket programından faydalanılarak korelasyon ve regresyon analizleri gerçekleştirilmiştir. Çalışmada ilk olarak verilerin normal dağılıma sahip olup olmadığını belirlemek için "çarpıklık ve basıklık" değerleri incelenmiştir. Tabachnik, Fidell ve Ullman (2007) verilerin çarpıklık ve basıklık değerlerinin $-1,5$ ile 1,5 arasında olması gerektiğini söylemiştir. Ölçek maddeleri incelendiğinde çarpıklık ve basıklık değerlerinin $-1,5$ ile $+1,5$ aralığında olduğu ve değişkenlere ait verilerin çoklu normal dağılım gösterdiği tespit edilmiştir. Çarpıklık ve basıklık değerlerinin uygunluğu belirlendikten sonra ölçeklerin geçerlilik ve güvenirliklerine yönelik analizler gerçekleştirilmiştir.

Tablo 1: Verilerin Dağılımı ve Güvenilirliğine İlişkin Bulgular

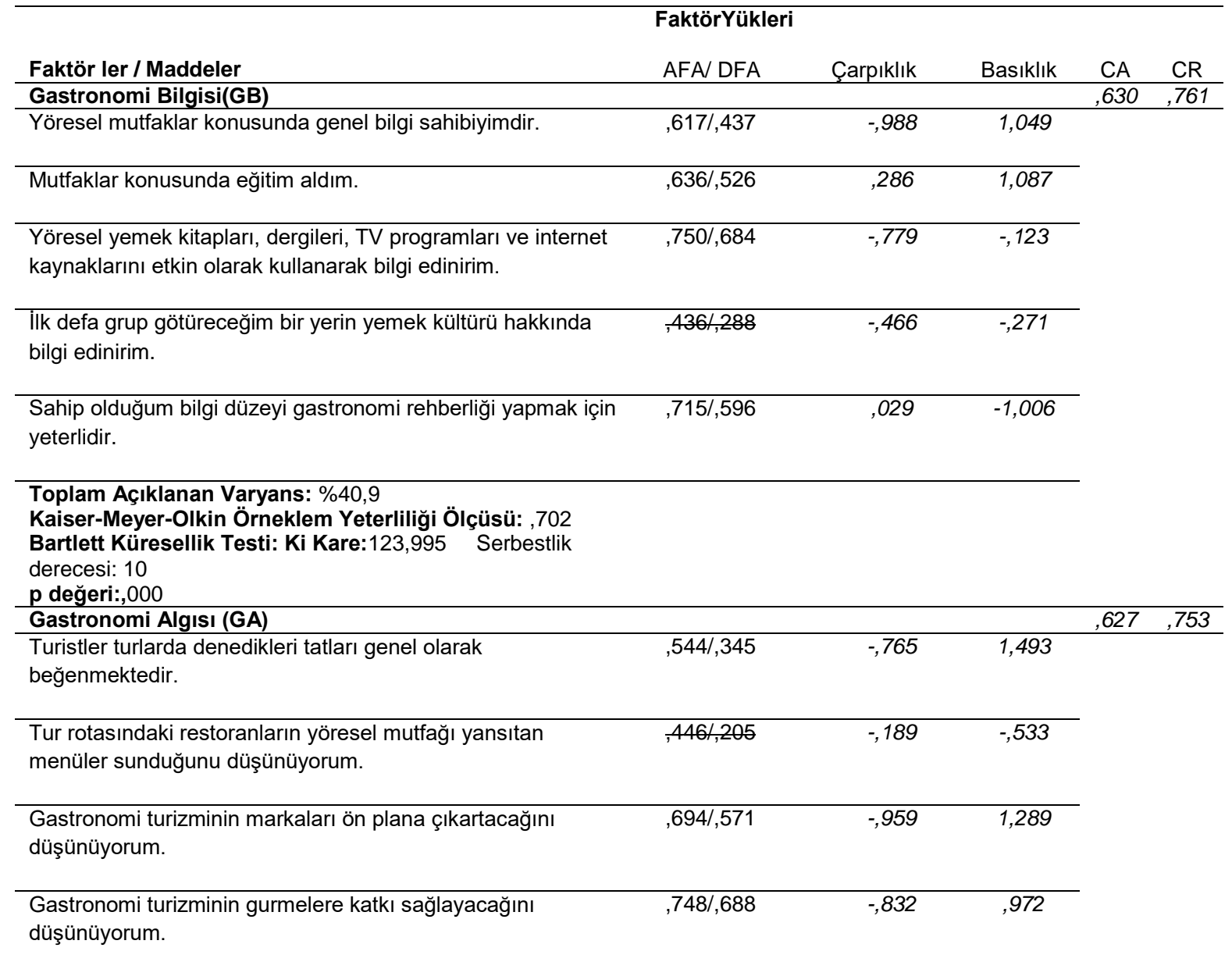


Tablo 1'in devamı

\begin{tabular}{|c|c|c|c|}
\hline $\begin{array}{l}\text { Gastronomi turlarının yöresel mutfak tanıtımına katkı sağlayacağını } \\
\text { düşünüyorum. }\end{array}$ & ,707/,648 &,- 728 & ,074 \\
\hline $\begin{array}{l}\text { Toplam Açıklanan Varyans: \%40,7 } \\
\text { Kaiser-Meyer-Olkin Örneklem Yeterliliği Ölçüsü: ,637 } \\
\text { Bartlett Küresellik Testi: Ki Kare: } 151,323 \text { Serbestlik derecesi:10 } \\
\text { p değeri:,000 }\end{array}$ & & & \\
\hline Tavsiye Etme Niyeti(TEN) & & 845 & ,896 \\
\hline Düzenlenecek yeni turlarda da yöresel mutfağı turistlere önereceğim. &, $727 /, 613$ &,- 355 &,- 763 \\
\hline $\begin{array}{l}\text { Tur rotasındaki restoranlara yöresel mutfağı yansıtan menüler } \\
\text { sunmalarını önereceğim. }\end{array}$ &, $872 /, 841$ &,- 885 & ,894 \\
\hline Yöresel mutfakta meydana gelecek yenilikleri takip edeceğim. & ,818/,743 &,- 561 & ,499 \\
\hline $\begin{array}{l}\text { Meslektaşlarıma turlarda yöresel mutfağa yer vermelerini tavsiye } \\
\text { edeceğim. }\end{array}$ &, $885 /, 858$ &,- 413 & ,382 \\
\hline $\begin{array}{l}\text { Toplam Açıklanan Varyans: \%68,52 } \\
\text { Kaiser-Meyer-Olkin Örneklem Yeterliliği Ölçüsü: ,796 } \\
\text { Bartlett Küresellik Testi: Ki Kare: } 366,297 \text { Serbestlik derecesi:6 } \\
\text { p değeri:,000 }\end{array}$ & & & \\
\hline
\end{tabular}

Tablo 1 incelendiğinde ölçeklere ait örneklem sayısının analiz yeterliliğini belirlemek için Kaiser-Meyer-Olkin (KMO) değerlerine bakılmıştır (GB: 0,702 GA: 0,637, TEN: 0,796). Verilerin faktör analizine uygunluğunu belirlemek için Bartlett's Küresellik Testi uygulanmış ve ölçeklere ait sonuçların anlamlı olduğu tespit edilmiştir. Elde edilen sonuçlar dahilinde KMO değerinin 0,60'tan yüksek olması ve Bartlett testinin anlamlı çıkması (Büyüköztürk, 2002), verilerinin faktör analizi için uygun olduğunu göstermiştir. Yakınsama geçerliliği için her bir ölçeğin ortalama açıklanan varyans (OAV) yükleri incelenmiştir. Bagozzi ve Youjae (1988) OAV değerlerinin 0,40' a kadar kabul edilebilir olduğunu ifade etmişlerdir. Elde edilen OAV değerleri incelendiğinde ölçeklerin yakınsama geçerliliğinin olduğu ifade edilebilir.

Ölçek maddelerinin faktör yükleri incelendiğinde Maddelerin yer aldıkları faktörlerdeki yük değerlerinin 0,30 ve üzerinde olması uygun bir ölçü olarak kabul edilmektedir (Kline, 1994). Tablo 1 incelendiğinde ölçek maddelerinden ikisi (Gastronomi Bilgisi 4. ifade ve Gastronomi Algısı 2. ifade) bu şartı sağlamadığı için ölçekten çıkarılmıştır.

Açıklayıcı ve doğrulayıcı faktör analizlerinin ardından ölçeklerin geçerlik ve güvenirliklerine yönelik analizler yapılmıştır. Ölçeklerin iç tutarlııı güvenirliğini tespit etmek amacıyla Cronbach Alfa (CA) ve birleşik güvenirlik (CR) değerleri incelenmiştir. Ölçeklerin CA (minimum: 0,62) ve CR (minimum: 0,75) değerlerinin kabul edilebilir sınırlar içinde olduğu belirlenmiştir (Hair vd., 2006; Kalaycı, 2009). 
Şekil 2: Ölçeklere Yönelik Uyum İyilik Değerleri

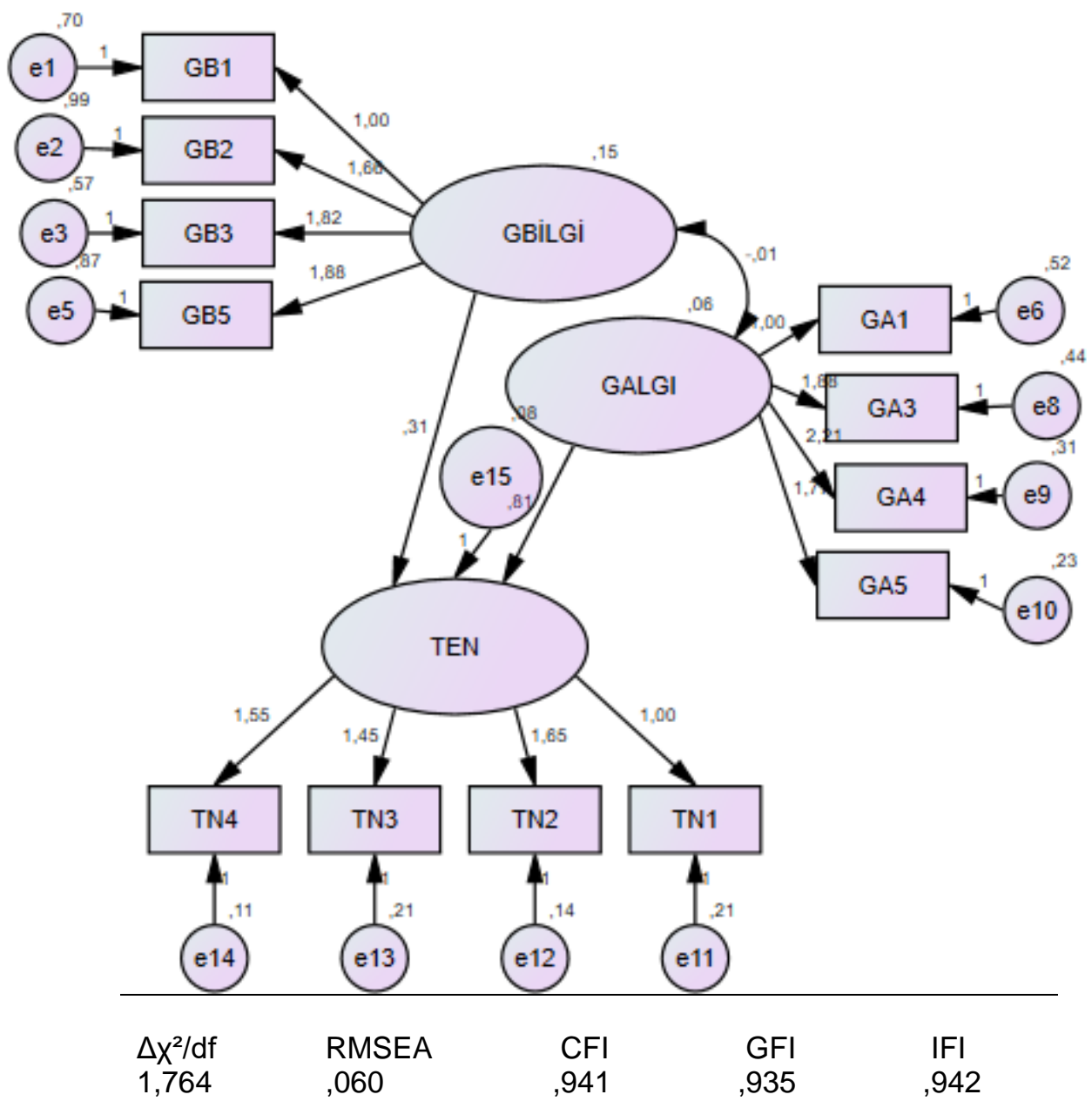

Şekil 2'de yer alan modele yönelik uyum iyilikleri incelendiğinde modelin kabul edilebilir değerlere sahip olduğu söylenebilir.

Tablo 2: Ölçeklere Yönelik Korelasyon Analiz Sonuçları

\begin{tabular}{cccc}
\hline Ölçek & $X$ & $S S$ & $T N$ \\
$G B$ & 3,27 &, 75 &, $206^{* *}$ \\
$G A$ & 4,09 &, 51 &, $439^{* *}$ \\
$T N$ & 4,27 &, 53 & - \\
\hline
\end{tabular}

Tablo 2 incelendiğinde GA, GB ve TN ölçeklerine yönelik ortalamaların genel olarak yüksek olduğu GA'nın GB'ye oranla daha yüksek skorlara sahip olduğu görülmektedir. Korelasyon ilişkisinde önem değeri anlamlı olan sonuçlar incelendiğinde GB-TN $(0,206)$ ve GA-TN $(0,439)$ arasında pozitif yönlü korelasyon ilişkisinin olduğu tespit edilmiştir. 
Çalışmada modele bağlı olarak oluşturulan iki hipotez test edilmiştir. Analiz sonucunda elde edilen bilgiler tablo 3'te sunulmuştur

Tablo 3: Çalışma Modeli Analizi

\begin{tabular}{cccc}
\hline Yol & Std. B & S.H & $P$ \\
GB------>TN &, 33 &, 099 &, 002 \\
GA------>TN &, 55 &, 244 & $* * *$ \\
\hline $\mathrm{p}<, 005$ & &
\end{tabular}

Tablo 3 incelendiğinde rehberlerin sahip olduğu gastronomi bilgisi ve gastronomi algısı ile tavsiye niyeti arasında pozitif yönlü ve anlamlı bir ilişkinin olduğu belirlenmiştir. Elde edilen sonuçlar neticesinde $\mathrm{H} 1$ ve $\mathrm{H} 2$ kabul edilmiştir. Bulgulara göre turist rehberlerinin tavsiye niyetlerinde gastronomi bilgisi ile gastronomi algısının önemli olduğu söylenebilir. Analizler incelendiğinde turist rehberlerinin tavsiye niyetlerinde sahip oldukları gastronomiye yönelik algılarının $(\beta$ : 0,55$)$, gastronomi bilgilerinden $(\beta: 0,33)$ daha fazla etkili olduğu tespit edilmiştir. Elde edilen sonuç neticesinde Kapadokya'da rehberlik yapan kişilerin gastronomi bilgisi ve algısının geliştirilmesi bölgenin tavsiye edilmesine katkı sağlayabilir. Bu nedenle bölgenin sahip olduğu gastronomik değerleri rehberlere öğretebilir ve gastronomiye yönelik olumlu algı meydana getirilebilirse gastronomi turizminin gelişmesine katkı sağlanabilecektir.

\section{Sonuç ve Öneriler}

Son yıllarda turistlerin farklı ülkelerin, bölgelerin, hatta şehirlerin sahip oldukları yemeiçme kültürüne karşı bir merak içerisinde olmaları gastronomi turizmine olan eğilimi artırmıştır (Göynüşen, 2011; Gökdeniz vd., 2015). Alternatif turizm çeşitleri arasında değerlendirilen gastronomi turizmi, turistlerin farklı destinasyonlara ait yemekleri tatma, yapılışlarını görme hatta deneyimlemek amacıyla bulundukları bölgeden başka bir bölgeye seyahat etmeleri olarak tanımlanabilir. Kapadokya bölgesinin de kendine has yerel yiyecekleri barındıran mutfak kültürünün olması bölgenin gastronomi turizmi potansiyeline sahip bir destinasyon olarak tercih edilmesinde etkili olabilir. Keskin vd., (2020) tarafından yapılan çalışmada Kapadokya bölgesini ziyaret eden turistlere çekici gelen unsurlar arasında yeme-içmenin de yer aldığı belirlenmiştir. Elde edilen bu veri bölgenin gastronomi amacıyla seyahatlere açık olabileceğini göstermektedir.

Kapadokya bölgesi; milyonlarca yıl önce coğrafi olaylar neticesinde meydana gelmiş doğal oluşumlarının yanı sıra kültür ve inanç turizmi açısından da dikkat çeken turistik destinasyonlardan biridir (Yetiş, 2015). Ayrıca bölgede yaşamış olan tarih öncesi uygarlıklar, hüküm sürmüş imparatorluklar ve göçlerle bölgeye gelen farklı toplumların kültür tarihi bölgenin sahip olduğu zengin bir mutfak kültürünün de zeminini oluşturmuştur. Kapadokya bölgesi mutfak kültüründe, bölgede yetişen sebzeler, meyveler, tahıllar ve et ürünlerinden oluşan yemeklerin ön planda olduğu görülmektedir. Bulgur çorbası, dolaz, ağpahla (kuru fasulye), bulamaç, aside, köftür Kapadokya mutfağı denilince akla gelen ilk yemeklerdir (Aras, 2016; Karakuş vd., 2019). Kapadokya'nın sahip olduğu bu zengin mutfak kültürünün tanıtılmasında işletmeler kadar turist rehberlerinin de önemli bir yeri olduğu aşikârdır. Çünkü turist rehberleri destinasyonu ziyaret eden turistlere tur boyunca bölge hakkında bilgi vermenin yanı sıra yeme-içme intiyaçlarını karışılmak için yöresel lezzetler hakkında da bilgiler vermektedirler. Başka bir ifadeyle bir nevi turistleri o bölgenin mutfak kültürü ile tanıştıran tanıım elçileri olmaktadırlar. Turist rehberlerinin bölgeyi iyi bilen kişiler 
olduğu düşünüldüğünde yemek kültürü ile ilgili olumlu ya da olumsuz değerlendirmelerin yapılmasında önemli bir rol oynamaktadır. Bu sebeple rehberlerin gastronomi turizmine yönelik bilgi seviyelerinin ve gastronomiye yönelik algılarının önemli olduğu görülmektedir.

Yapılan bu çalışmayla turistik açıdan önemli bir destinasyon olan Kapadokya bölgesinde profesyonel turist rehberi olarak görev yapan rehberlerin gastronomi bilgisi ve gastronomiye yönelik algılarının ne düzeyde olduğu ve bu unsurların tavsiye niyetine etkisi belirlenmeye çalışılmıştır. Çalışma dahilinde katılımcıların gastronomi bilgisi $(3,27)$ ve gastronomi algısı $(4,09)$ ortalamalarının ortalama değerin üzerinde olduğu söylenebilir. Belirlenen amaç doğrultusunda çalışma modeli ve modele bağlı kalarak iki hipotez belirlenmiştir. Hipotezlere yönelik yapılan analiz sonuçlarına göre, rehberlerin sahip olduğu gastronomi bilgisi ve gastronomi algısı ile tavsiye niyeti arasında pozitif yönlü ve anlamlı bir ilişkinin olduğu belirlenmiştir. Diğer bir önemli bulgu ise turist rehberlerinin sahip olduğu gastronomi algılarının tavsiye niyetlerinde daha fazla etkili olduğu yönündedir.

Yapılan bu çalışma sonucunda turist rehberlerinin destinasyonların yemek kültürünü tanıtmada etkili bir role sahip olduklarını ortaya koymaktadır. Bu nedenle üniversitelerin turizm veya turist rehberliği bölümlerinde gastronomi ve Türk mutfak kültürüne yönelik derslere daha fazla yer verilmesi sağlanmalıdır. Çünkü günümüzde artık turistler sadece yöresel lezzetleri deneyimlemek için bile seyahat etmekte ve bunun içinde bir gastronomi rehberi talep edebilmektedirler. Bu durum gastronomi alanında bilgi sahibi olan rehberlere talebi artırmaktadır. Rehberler bölge gastronomisini turistlere daha doğru bir şekilde aktararak bölge imajına da olumlu bir katkı sağlayabilir. Oluşturulan bu olumlu imaj turistlerin bölgeyi tekrar ziyaret etmelerinde ve çevrelerine tavsiye etmelerine etki edebilir.

Bir diğer öneri olarak turist rehberi adaylarına eğitim dönemlerinde çıktıkları bölgesel turlarda ziyaret ettikleri yörelerin yeme-içme geleneklerinin de sistemli bir şekilde öğretilmesi sağlanabilir. Bu şekilde turist rehberi adayları bölgelerin gastronomi değerleri hakkında daha fazla bilgi sahibi olabilir ve mesleğe başladıklarında öğrenmiş oldukları bilgileri turistlere anlatabilir. Bunun yanı sıra turist rehberlerine yönelik hazırlanan kaynaklarda bölgelerin gastronomi unsurlarına daha fazla yer verilerek gastronomi odaklı çalışan rehber sayısı artırılabilir.

Bölgenin gastronomi değerlerinin rehberler vasıtasıyla aktarılması yöresel ve unutulmaya yüz tutmuş tatların ortaya çıkarılmasında katkı sağlayabilir. Bu sayede de yöresel ürün pazarları canlanıp küçük ölçekli işletmelerin hayatta kalma şansları artırılabilir. Ayrıca bölgede yerel ürün üretiminde artış sağlanarak tarım ve hayvancılığın gelişimine katkıda bulunulabilir. Dolayısıyla turizmin çarpan etkisi gastronomi ile artırılabilir.

Kapadokya bölgesinde yerel mutfağı tanıtan restoranlardaki şefler ile turist rehberleri arasında daha sıkı bir iletişim sağlanarak, turist rehberlerinin hangi yiyecekleri nasıl tanıtacaklarına dair asıl kaynağından bilgi almaları, turist rehberlerinin iş hayatına başlamadan önce çalışacakları bölgenin gastronomisi hakkında turistlere yeterli bilgi verebilecek düzeyde oryantasyon eğitimi almaları bölgenin gastronomisinin tanıtımında etkili olabilir.

Sonuç olarak hazırlanan bu çalışma Kapadokya bölgesinde profesyonel turist rehberi olarak çalışanların gastronomi bilgi ve algılarının tavsiye niyetine etkisini incelemiştir. Yapılacak diğer çalışmalarda turist rehberlerinin gastronomi bilgi ve 
algılarının müşteri odaklı memnuniyete katkıları araştırılabilir ve başka bölge rehberleri ile karşılaştırmalı çalışmalar yürütülebilir. Turist rehberlerinin sosyal medya platformlarında gastronomi destinasyonları hakkında bilgi vermelerinin turistlerde ziyaret veya tavsiye niyeti oluşumunda bir etkisi olup olmadığı araştırılabilir. Turistlerin yerel yiyecekler hakkında gastronomi rehberlerine ne sıklıkla hangi tür sorular sordukları ve bu sorular doğrultusunda turistlerin soyut bilgi edinmek için mi yoksa destinasyon alanında deneyim gerçekleştirmek için mi iletişime geçtikleri araştırılabilir. Ayrıca üniversitelerde turizm-turist rehberliği bölümlerindeki müfredatlar incelenerek müfredatlarda gastronomi ve rehberlik ilişkisine yönelik eğitimin olup olmadığı analiz edilebilir ve bu alana yönelik lisansüstü eğitim basamaklarında turist rehberliğigastronomi ile ilgili çalışmalar yapılarak alana yönelik bilimsel temel geliştirilebilir. Bir diğer öneri olarak turist/turizm rehberliği özel ilgi turizminde olduğu gibi dallara ayrılabilir ve bu dallardan birisini gastronomi rehberliği oluşturabilir. Bu sayede gastronomi alanında uzmanlaşmış rehberler yetiştirilebilir ve ülke-bölge mutfaklarının profesyonel olarak tanıtılması sağlanabilir.

\section{Kaynakça}

Akay, B. ve Özöğütçü, B. (2018), 'Turist Rehberlerinin Turlarda Gastronomiyi Kullanmalarına Yönelik Bir Araştırma', Journal of Tourism and Gastronomy Studies, 6(3), ss. 143-153.

Akbaba, A. ve Kendirci, P. (2016), 'Gastronomi Turizmi ve Coğrafi İşaretlemeli Ürünler' İçinde O.N. Özdoğan (Editör), Yiyecek Içecek Endüstrisinde Trendler 2, ss. 113129, Ankara, Detay.

Aksoy, M. ve Sezgi, G. (2015), 'Gastronomi Turizmi ve Güneydoğu Anadolu Bölgesi Gastronomik Unsurları', Journal of Tourism and Gastronomy Studies, 3(3), ss. 79-89.

Anderson, E.W., Fornell, C. ve Mazvancherly, S.K. (2004), 'Customer Satisfaction and Shareolder Value', Journal of Marketing, 68(4), ss. 172-185.

Aras, N. (2016), Kapadokya Mutfağı-1, Gastro Metro Dergisi, İstanbul, Apa Unıprınt.

Ardıç, Ş. (2015), 'Kapadokya Yemek Kültürü ve Mustafapaşa Beldesi (Sinasos) Örneği', Journal of Tourism and Gastronomy Studies, 3(2), ss. 12, 19.

Aslan, Z., Güneren, E. ve Çoban, G. (2014), 'Destinasyon Markalaşma Sürecinde Yöresel Mutfağın Rolü: Nevşehir Örneği', Journal of Tourism and Gastronomy Studies, 2(4), ss. 3-13.

Aslan, Z. ve Çokal, Z. (2016), 'Profesyonel Turist Rehberinin Kültürel Değerlere Katkısına İlişkin Turist Algılamaları', Journal of Tourism and Gastronomy Studies, 4(1), ss. 53-69.

Bagozzi, R.P. ve Youjae, Y.I. (1988) 'On the Evaluation of Structural Equation Models', Journal of the Academy of Marketing Science, 16, ss. 74-94.

Bilgili, B., Yağmur, Ö. ve Yazarkan, H. (2012), 'Turistik Ürün Olarak Festivallerin Etkinlik ve Verimliliği Üzerine Bir Araştırma (Erzurum-Oltu Kırdağ Festivali Örneği)', Uluslararası Sosyal ve Ekonomik Bilimler Dergisi, 2(2), ss. 117-124.

Bucak, T. ve Aracı, Ü.E. (2013). 'Türkiye'de Gastronomi Turizmi Üzerine Genel Bir Değerlendirme', Balıkesir Üniversitesi Sosyal Bilimler Enstitüsü Dergisi, 16(30), ss. 203-216.

Büyüköztürk, Ş. (2002), Veri Analizi El Kitabı, Ankara: Pegem.

Eren, R. (2016), 'Gastronomi İmajı: Türkiye Restoranlarının Tripadvisor Yorumlarının İçerik Analizi', Turizm Akademik Dergisi, 4(2), ss. 121-138.

Güneren Ö.E. ve Yılmaz, V. (2016), 'Konaklama İşletmelerinin Rekabet Gücünü Belirleyen Faktörler Üzerine Nevşehir İlinde Bir Uygulama', Journal of Multidisciplinary Academic Tourism, 1 (1), ss. 61-80. 
Gürsoy, D. ve McCleary, K. (2004), 'An Integrated Model of Tourists' Information Search Behaviour', Annals of Tourism Research, 31, ss. 353-373.

Göynüşen, S. E. (2011) Edirne'deki Gastronomik Kültürün Kentin Pazarlama ve Markalaşmasına Etkileri, Yayınlanmamış Yüksek Lisans Tezi, Trakya Üniversitesi, Sosyal Bilimler Enstitüsü, Edirne.

Gökdeniz, A., Erdem, B., Dinç, Y. ve Çelik Uğuz, S. (2015), 'Gastronomi Turizmi: Ayvalık'ta Yerli Turistler Üzerinde Görgül Bir Araştırma', Journal of Tourism and Gastronomy Studies, 3(1), ss. 14-29.

Hair, F. JR. Black, W. C. Babin, B. J. Anderson, R. E. ve Tatham, R. L. (2006), Multivariate Data Analysis (6th ed.), New Jersey: Prentice Hall.

Hjalager, A.M. ve Corigliano, M.A. (2000), 'Food For Tourist-Determinants of An Image', International Journal of Tourism Research, 2, ss. 281-293.

Horng, J.S. ve Tsai, C.T. (2012), 'Constructing Indicators of Culinary Tourism Strategy: An Application of Resource-Based Theory', Journal of Travel and Tourism Marketing, 29(8), ss. 796-816.

İrigüler, F. ve Güler, M.E. (2017), 'Tourist Guides' Perceptions on Gastronomic Tourism in Turkey', Journal of Tourism and Gastronomy Studies, 5(1), ss. 3-19.

Kalaycı, Ş. (2009), 'Spss Uygulamalı Çok Değişkenli Istatistik Teknikleri', Ankara: Asil.

Karakuş, Y., Onat, G., ve Güneren Ö.E. (2019). 'Yerel Halkın Gastronomi Turizmi Kavramına Bakış Açılarının Değerlendirilmesi', IV th International Gastronomy Tourism Studies Congress Proceeding Book, Nevşehir.

Karamustafa, K. ve Çeşmeci, N. (2006), 'Paket Tur Operasyonunda Turist Rehberlerinin Karşılaştıkları Yönetsel Sorunlar Üzerine Bir Araştırma', Anatolia: Turizm Araştırmaları Dergisi, 17(1), ss. 70-86.

Katlav, E.Ö., Eren, F.Y. \& Tuna, M. (2019), 'Kapadokya'da bağcılığın Gastronomi Turizmi Açısından Değerlendirilmesi', Journal of Tourism and Gastronomy Studies, 7(3), ss. 2167-2186.

Keskin, E., Sezen, N. ve Dağ, T. (2020), 'Unutulmaz Turizm Deneyimi, Müşteri Memnuniyeti, Tekrar Ziyaret ve Tavsiye Etme Niyeti Arasındaki İlişkiler: Kapadokya Bölgesini Ziyaret Eden Turistlere Yönelik Araştırma', Journal of Recreation and Tourism Research, 7(2), ss. 239-264.

Kivela, J. ve Crotts, J.C. (2006), 'Tourism and Gastronomy: Gastronmy's Influence on How Tourist Experience a Destination', Journal of Hospitalty and Tourism Research, 30(3), ss. 354-377.

Kline, P. (1994), An Easy Guide to Factor Analysis. New York: Routledge.

Kozan, G. Y., Özdemir, S. S. ve Günlü, E. (2014), 'Turizm Yazında "Deniz Turizminin Olgusal Gelişimi', Dokuz Eylül Üniversitesi Denizcilik Fakültesi Dergisi, 6(2), ss. 115-129.

Köroğlu, A., Köroğlu, O. ve Sarıoğlan, M. (2007), 'Türk Mutfağının Tanıtılmasında Profesyonel Turist Rehberlerinin Rolüne İlişkin Amprik Bir Çalışma', I. Ulusal Gastronomi Sempozyumu ve Sanatsal Etkinlikler, 4-5 Mayıs. Antalya.2011.

Ling, T.P, Noor, S.M, Lim, K.Y. ve Mohamed, R. (2011), 'Tour Guides As Interpreters of Cultural Heritage in Promoting Mindful Tourists for Sustainable Tourism in Malaysia', Proceedings of 2nd Regional Conference on Tourism Research. Penang, Universiti Sains Malaysia.

Özaltaş Serçek, G. ve Serçek. S. (2015), 'The role and Importance of Gastronomy Tourism on Destination Branding', Journal of Tourism Theory and Research, $1(1)$, ss. 15-28.

Özöğütcü, B. (2018), Turist Rehberlerinin Gastronomi Bilgisi ve Algısının Tavsiye Niyetine Etkisi, Yayınlanmamış Yüksek Lisans Tezi, Kırklareli Üniversitesi, Sosyal Bilimler Enstitüsü, Kırklareli. 
Solunoğlu, A. (2019), 'The Effect of Gastronomic Brand Image', İçinde İ. Yazıcıoğlu, Ö. Yayla, A. Solunoğlu (Editörler), In: Current Issues in Tourism and Hospitality Management, SRA Academic Publishing. Lithuanian.

Tabachnick, B. G., Fidell, L. S., ve Ullman, J. B. (2007), 'Using Multivariate Statistics' (Vol. 5), Boston, MA, Pearson.

TUREB, (2020). http://tureb.org.tr/tr/Rehberlstatistik/ (Erişim Tarihi: 14.02.2020).

Uslu, A. ve Kiper, T. (2006), 'Turizmin Kültürel Miras Üzerine Etkileri: Beypazarı/Ankara Örneğinde Yerel Halkın Farkındalığı', Tekirdağ Ziraat Fakültesi Dergisi, 3(3), ss. 305-314.

Yayla, Ö. ve Çetiner, H. (2019), 'Boş Zamanların Değerlendirilmesinde Etkili Olan Faktörlerin Boş Zaman Tatminine Etkisi', Turizm Akademik Dergisi, 6(1), ss. 219-228.

Yılmaz, G. ve Özdemir, B. (2015), 'Yerel Gastronominin Tanıtım Materyallerindeki Yeri: Kapadokya Bölgesi Üzerine Bir Araştırma', I. Eurasia Tourism Congress: Current Issues, Trends, and Indicators, May 28-30, Konya, Turkey, ss. 760-780.

Yılmaz, G. (2017), 'Gastronomi ve Turizm İlişkisi Üzerine Bir Değerlendirme', Seyahat ve Otel İşletmeciliği Dergisi, 14(2), ss. 171-191.

Zengin, B. ve Eker, N. (2014), 'Alternatif Turizm Kapsamında Kültür Turizminin Sürdürülebilirliğinde Turist Rehberlerinin Rolü', XIII. Geleneksel Turizm Paneli, https://www.researchgate.net/profile/Dr_Burhanettin_Zengin/publication/261722 480 The Role of Tourist_Guide at the Cultural Context_of Alternative_Touri sm_Tourist_Guide_of_Sustainability_in_Tourism_A_Case_Study_-

Alternatif_Turizm_Kapsaminda_Kultur_Turizminin_Surdurulebilirliginde_/links/0 Ob7d53552af31d829000000/The-Role-of-Tourist-Guide-at-the-Cultural-Contextof-Alternative-Tourism-Tourist-Guide-of-Sustainability-in-Tourism-A-Case-StudyAlternatif-Turizm-Kapsaminda-Kueltuer-Turizminin-Suerdueruelebilirlig.pdf (Erişim Tarihi: 15.03.2020).

T.C.

NEVŞEHIR HACI BEKTAS VELI ONNIVERSITESI ETIK KURUL KARARI

Karar Tarihi: $\mathbf{0 2 . 0 3 . 2 0 2 0}$ Toplantı Savis: 07

Öniversitemiz Turizm Fakültesi Dr. Öğr. Övesi Emrah KESKì'in "Turist Rehberlerinin Gastronomi Bilgisini Ölcmeve Yönelik Arastırma" isimli arastırma projesi hakkında Turizm Fakültesi Dekanlı̆ından alınan 28.02 .2020 tarih ve E.6084 savilı vazinin görüsülmesi.

2020.07.39. Oniversitemiz Turizm Fakültesi Dr. Ögr. Oyesi Emrah KESKIN'in "Turist Rehberlerinin Gastronomi Bilgisini Olç̧meye Yőnelik Araştırma" isimli araștırma projesi hakkında Turizm Fakultesi Dekanlıgından alınan 28.02,2020 tarih ve E.6084 sayilı yazı gőrüșüldũ.

Yapılan göruissmeler sonucunda, aşaǧidaki tabloda isimleri belirtilen araştırmacılar tarafindan hazırlanan "Turist Rehberlerinin Gastronomi Bilgisini Ölçmeye Yönelik Araştırma" isimli araştırma projesi dosyası ve ilgili belgeler araştımanın gerekçe, amaç, yaklaşım ve yöntemleri dikkate ałınarak incelenmiş olup, projenin gerçekleștirilmesinde etik sakınca bulunmadığına kurulumuz üyeleri tarafindan oy birligi ile karar verilmiștir.

\begin{tabular}{|l|l|}
\hline YURÜTÜCÜ & ARASTTIRMACIUZMAN \\
\hline Dr. Ögr. Uyesi Emrah KESKIN & $\begin{array}{l}\text { 1-Arș. Gör. Dr. Sule ARDIÇ YETIS } \\
\text { 2-Bülent YORGANCI (Ogrenci) }\end{array}$ \\
\hline
\end{tabular}

